\title{
High-dose treatment with ADXS11-001, a listeria monocytogenes (Lm)-listeriolysin O (LLO) immunotherapy, in women with cervical cancer
}

Sharad Ghamande ${ }^{1 *}$, David Mauro², Cheryl Price ${ }^{1}$, Donna Wheatley ${ }^{1}$, John Janik', Samir N Khleif ${ }^{1}$

From 30th Annual Meeting and Associated Programs of the Society for Immunotherapy of Cancer (SITC 2015) National Harbor, MD, USA. 4-8 November 2015

\begin{abstract}
Introduction
Survival of patients with persistent and recurrent cervical cancer is dismal, and improvement remains a large unmet need. ADXS11-001 is a live, attenuated, bioengineered $L m$-LLO immunotherapy for the treatment of human papillomavirus (HPV)-associated cancers such as cervical cancer. ADXS11-001 secretes an HPV-E7 tumor antigen as a truncated LLO-E7 fusion protein that stimulates antitumor immunity through $\mathrm{T}$ cells, while reducing immune tolerance via T-regulatory and myeloid-derived suppressor cells. ADXS11-001 has been shown to be safe and effective in women with recurrent/refractory cervical cancer. This Phase I study evaluates whether a higher ADXS11-001 dose than that currently used in Phase II trials is safe and well tolerated.
\end{abstract}

\section{Methods}

This is a Phase I, dose-escalation, open-label study (NCT02164461) enrolling women aged $\geq 18$ years with persistent, metastatic, or recurrent squamous/adenocarcinoma of the cervix and documented disease progression (not amenable to surgery/standard radiotherapy). Additional eligibility criteria include: measurable and/or evaluable disease per Response Evaluation Criteria in Solid Tumors (RECIST v1.1); Eastern Cooperative Oncology Group (ECOG) performance status of $0-1$; and $\leq 2$ prior treatments for metastatic disease. The primary endpoint is the safety and tolerability of ADXS11-001; secondary endpoints include evaluating tumor response and progression-free survival, and assessing correlative immunologic studies. Patients will receive ADXS11-001 every 3 weeks during a 12 -week treatment cycle. Dose escalation is performed using the $3+3$ design in 2 doses: $5 \times 10^{9}$ colony-forming units (CFU; Dose Level 1) and $1 \times 10^{10}$ CFU (Dose Level 2). The recommended Phase II dose will be selected based on an observed dose-limiting toxicity (DLT) rate of $<33 \%$. Efficacy is assessed using RECIST v1.1 and immune-related RECIST. Blood samples will be collected in cycle 1 only and used for immune monitoring and cytokine/chemokine analysis.

\section{Results}

Enrollment into Dose Level 1 is complete $(n=6)$. Initially 3 patients were enrolled into the first dose cohort; 1 patient experienced grade 3 hypotension as a DLT, resulting in 3 additional patients being enrolled. The mean age is 51.3 years, $66.7 \%(n=4)$ had ECOG 0 at baseline, and $83.3 \%(n=5)$ patients have squamous histology. All patients received prior cisplatin-based concurrent chemoradiation, plus a median of 1.5 (range $0-5)$ lines of systemic chemotherapy. A total of 16 doses of ADXS11-001 have been safely administered; accrual for Dose Level 2 is starting. Updated data on the determination of the maximum tolerated dose and efficacy of ADXS11-001 will be presented.

\section{Trial registration}

ClinicalTrials.gov identifier NCT02164461.

\section{Authors' details}

${ }^{1}$ GRU Cancer Center, Georgia Regents University, Augusta, GA, USA. ${ }^{2}$ Advaxis, Inc., Princeton, NJ, USA.

Published: 4 November 2015

${ }^{1}$ GRU Cancer Center, Georgia Regents University, Augusta, GA, USA

Full list of author information is available at the end of the article 
doi:10.1186/2051-1426-3-S2-P151

Cite this article as: Ghamande et al: High-dose treatment with ADXS11001, a listeria monocytogenes (Lm)-listeriolysin O (LLO) immunotherapy, in women with cervical cancer. Journal for ImmunoTherapy of Cancer 2015 3(Suppl 2):P151.

Submit your next manuscript to BioMed Central and take full advantage of:

- Convenient online submission

- Thorough peer review

- No space constraints or color figure charges

- Immediate publication on acceptance

- Inclusion in PubMed, CAS, Scopus and Google Scholar

- Research which is freely available for redistribution

Submit your manuscript at www.biomedcentral.com/submit
C BioMed Central 